\title{
Willingness to pay to avoid metastatic breast cancer treatment side effects: results from a conjoint analysis
}

\author{
Deepa Lalla', Rashad Carlton ${ }^{2 *}$ Eduardo Santos ${ }^{3}$, Thomas Bramley ${ }^{2}$ and Anna D'Souza ${ }^{2}$
}

\begin{abstract}
Purpose: Metastatic breast cancer (MBC) patients are treated with a variety of regimens with differing side effects that can reduce the patients' quality of life. This study assessed the willingness to pay (WTP) to avoid side effects related to MBC treatment using conjoint analysis.

Methods: An online, self-administered conjoint analysis survey of US adult female MBC patients was conducted to elicit preferences for MBC treatment side effects. Attributes included in the analysis were hair loss, diarrhea, fatigue, nausea, tingling in hands and feet, pain, risk of infection, and out-of-pocket costs. Fifteen choice-based conjoint questions were presented where patients selected the most preferred therapy. A partial profile design was used to allow for each treatment description to be made with 3 instead of all 8 attributes. The attribute choices for each question included 2 side effects and a yearly out-of-pocket price.

Results: There were 298 respondents. MBC patients were willing to pay (US\$) $\$ 3,894$ to avoid severe diarrhea, $\$ 3,479$ to avoid being hospitalized due to infection, $\$ 3,211$ to avoid severe nausea, $\$ 2,764$ to avoid severe tingling in hands and feet, $\$ 2,652$ to avoid severe fatigue, $\$ 1,853$ to avoid obvious hair loss, and $\$ 1,458$ to avoid severe pain. The most important attributes when selecting a therapy for MBC in terms of average utility were risk of infection, diarrhea, and nausea.
\end{abstract}

Conclusions: MBC patients were willing to pay significant amounts to avoid side effects associated with MBC treatment, with patients willing to pay the most to avoid diarrhea, risk of infection, and nausea.

Keywords: Willingness to pay; Conjoint analysis; Metastatic breast cancer

\section{Introduction}

Breast cancer is the most frequently diagnosed cancer in women after skin cancer. It is estimated that 226,870 women will be diagnosed with and 39,150 women will die of breast cancer in 2012 (Howlader et al. 2012). The overall 5-year relative survival for breast cancer from 2002 to 2008 was $89.0 \%$. The majority of women with breast cancer will present with the disease localized to the primary site $(60 \%)$ or with spread to regional lymph nodes $(33 \%)$, where the 5 -year relative survival is over $80 \%$ (Howlader et al. 2012). Approximately $5 \%$ of women with breast cancer present with more severe metastatic disease at diagnosis (Howlader et al. 2012). The 5-year survival rate for

\footnotetext{
* Correspondence: rashad.carlton@xcenda.com

${ }^{2}$ Xcenda, Palm Harbor, FL, USA

Full list of author information is available at the end of the article
}

women with metastatic breast cancer $(\mathrm{MBC})$ at diagnosis is only $23.8 \%$ (Howlader et al. 2012). Newer chemotherapy agents and hormone agents used for the treatment of $\mathrm{MBC}$ have led to significant improvements in patients' survival (Pal et al. 2012; Andre et al. 2004; Chia et al. 2007). As survival improves, patients are being exposed to therapy for longer periods of time, and quality of life optimization is a goal of treatment. Agents used in the treatment of MBC may have associated side effects that can affect and reduce quality of life for patients with MBC (Romond et al. 1995; Piccart-Gebhart et al. 1995; Shapiro and Recht 2001; Tannock et al. 1998; Osaba et al. 2003). These associated side effects, which vary by agent, can be an important consideration when evaluating the best regimen for a patient.

\section{空}

(C) 2014 Lalla et al.; licensee Springer. This is an Open Access article distributed under the terms of the Creative Commons Attribution License (http://creativecommons.org/licenses/by/4.0), which permits unrestricted use, distribution, and reproduction in any medium, provided the original work is properly credited. 
Lindley et al. showed that women who experience severe disruptions in quality of life are less willing to receive additional treatment for an extension of life by 6 months compared with women who experienced no or little disruption in normal life (Lindley et al. 1998). Assessing the perceived value of a lower risk of toxicity provides additional information on how patients view the tolerability of chemotherapy agents, potentially assisting in the selection of preferred agents. The objective of this analysis was to assess the importance of MBC treatment side effects and to assess the willingness to pay (WTP) to avoid these side effects.

\section{Methods}

A survey was developed using conjoint analysis to elicit preferences or utilities for treatments for MBC based on the side-effect profile of the treatment. Conjoint analysis involves comparing hypothetical scenarios by ranking, rating, or choosing a particular scenario (Phillips et al. 2002). Conjoint analysis elicits preferences by asking respondents to evaluate alternatives consisting of different combinations of attributes (Phillips et al. 2002). Respondent choices indicate the relative importance of the product attributes and provide data for estimating utilities. The conjoint analysis technique is based on economic theory and the assumption that individuals maximize a preference (or utility) function (Phillips et al. 2002). Conjoint analysis can also be used to estimate how individuals trade between attributes; for example, the rate at which they are willing to give up one unit of an attribute for an increase in another attribute (Ryan 1999). This is known as the marginal rate of substitution (MRS). When applied to the current study, treatments for $\mathrm{MBC}$ were defined in terms of their side-effect profile, with the side effects constituting the attributes of the treatment. The conjoint analysis technique was then used to obtain utilities for each of the treatment-related side effects.
The conjoint analysis technique consists of 5 steps (Ryan and Farrar 2000). First, the attributes are defined. Seven side effects of MBC treatments were chosen as attributes for the survey. The side effect attributes were hair loss, fatigue, nausea, pain, diarrhea, risk of infection, and tingling in hands and feet. Additionally, cost was included as an attribute to allow for calculation of the WTP to avoid side effects. Second, the levels for each of the attributes are set. Levels for the attributes were based on severity of mild/low, moderate/medium, or severe/high (Table 1). Attributes and levels were selected based on the literature and in collaboration with clinicians based on the side effects and severity levels commonly seen in clinical practice when treating $\mathrm{MBC}$ patients. Attributes were described in non-medical, lay terminology so that they could be easily understood by patients (eg, "hair loss" instead of "alopecia").

Third, scenarios are created. The 8 attributes in the analysis, each with 2 or 3 levels, give rise to 2,916 possible combinations $\left(3^{6} \times 2^{2}=2,916\right)$. It is implausible to assess the utility for each respondent on all attributes and levels with such a large number of possible combinations. An orthogonal main effects design was therefore used to reduce the number of possible combinations to a manageable level while still being able to infer utilities for all possible scenarios (Ryan 1999). The orthogonal design resulted in the creation of 15 survey versions for each respondent. Previous research suggests that individuals can manage between 9 and 16 pairwise comparisons before they become tired or bored (Pearmain et al. 1991). Additionally, a partial profile design was chosen over a full-profile design that allowed for treatment descriptions to be made with 3 instead of all 8 attributes (Ryan and Farrar 2000). Each treatment choice was described in terms of 2 side effects (randomly chosen) and an out-of-pocket cost level.

Fourth, preferences are established (Ryan and Farrar 2000). In this analysis, we employed the discrete-choice

Table 1 Attributes and levels of side effects

\begin{tabular}{|c|c|c|c|}
\hline \multirow[t]{2}{*}{ Attribute } & \multicolumn{3}{|c|}{ Level of severity } \\
\hline & Mild/Low & Moderate/Medium & Severe/High \\
\hline Hair loss & None/not noticeable & - & Obvious \\
\hline Fatigue & None/full activity & I often need a nap to reset myself & Major impact on my activity level \\
\hline Nausea & None/easy to ignore & Manageable with medication/still eating & Can't eat \\
\hline Pain & None/easy to ignore & $\begin{array}{c}\text { Manageable with OTC medication } \\
\text { (eg, Advil, Tylenol) }\end{array}$ & Need prescription-strength medication \\
\hline Diarrhea & 2 stools or less/day & $3+$ loose stools per day & $\begin{array}{l}\text { Unable to leave the house due to frequency } \\
\text { and urgency of diarrhea }\end{array}$ \\
\hline Risk of infection & None/modest & - & Hospitalized due to infection \\
\hline Tingling in hands and feet & None/easy to ignore & Bothersome but manageable & $\begin{array}{l}\text { Interferes with activities of daily living } \\
\text { (eg, getting dressed) }\end{array}$ \\
\hline Out-of-pocket cost & $\$ 500$ & $\$ 1,000$ & $\$ 3,000$ \\
\hline
\end{tabular}

Key: OTC - over-the-counter. 
Table 2 Description of study sample

\begin{tabular}{|c|c|}
\hline Characteristic & Percent of respondents $(n=298)$ \\
\hline \multicolumn{2}{|l|}{ Insurance Status } \\
\hline Private insurance & $57.1 \%$ \\
\hline Medicare & $13.8 \%$ \\
\hline Medicare w/supplemental & $14.8 \%$ \\
\hline Medicaid & $7.4 \%$ \\
\hline Veterans Affairs & $1.3 \%$ \\
\hline Other & $5.7 \%$ \\
\hline \multicolumn{2}{|l|}{ Marital Status } \\
\hline Single & $18.5 \%$ \\
\hline Married & $57.5 \%$ \\
\hline Divorced & $18.8 \%$ \\
\hline Widowed & $5.5 \%$ \\
\hline \multicolumn{2}{|l|}{ Race } \\
\hline White & $83.9 \%$ \\
\hline Black & $9.1 \%$ \\
\hline Asian & $1.3 \%$ \\
\hline Hispanic & $4.4 \%$ \\
\hline Other & $1.3 \%$ \\
\hline \multicolumn{2}{|l|}{ Region } \\
\hline Northeast & $28.9 \%$ \\
\hline Midwest & $25.5 \%$ \\
\hline South & $23.5 \%$ \\
\hline West & $22.1 \%$ \\
\hline \multicolumn{2}{|l|}{ Area of Residence } \\
\hline Rural & $20.5 \%$ \\
\hline Suburban & $53.0 \%$ \\
\hline Mid-sized urban & $10.1 \%$ \\
\hline Urban & $16.4 \%$ \\
\hline \multicolumn{2}{|l|}{ Education Level } \\
\hline Some high school & $3.0 \%$ \\
\hline High school & $21.8 \%$ \\
\hline Trade school & $12.1 \%$ \\
\hline Associate degree & $19.5 \%$ \\
\hline Bachelor degree & $27.5 \%$ \\
\hline Graduate degree & $16.1 \%$ \\
\hline \multicolumn{2}{|l|}{ Age } \\
\hline 30 years or younger & $3.0 \%$ \\
\hline $31-40$ years & $21.8 \%$ \\
\hline $41-50$ years & $12.1 \%$ \\
\hline $51-60$ years & $19.5 \%$ \\
\hline $61-70$ years & $27.5 \%$ \\
\hline $71+$ years & $16.1 \%$ \\
\hline \multicolumn{2}{|l|}{ Household Income } \\
\hline Under $\$ 10,000$ & $7.1 \%$ \\
\hline
\end{tabular}

Table 2 Description of study sample (Continued)

\begin{tabular}{ll}
\hline$\$ 10,000-\$ 25,000$ & $13.4 \%$ \\
$\$ 26,000-\$ 50,000$ & $26.5 \%$ \\
$\$ 51,000-\$ 75,000$ & $23.5 \%$ \\
$\$ 76,000-\$ 100,000$ & $14.4 \%$ \\
Over $\$ 100,000$ & $15.1 \%$ \\
\hline
\end{tabular}

method where respondents were presented with 3 treatment choices for each conjoint question and were asked to choose their preferred treatment. The discrete choice approach was preferred as it mimics the manner in which decisions are made in real life and is based on random utility theory (Ratcliffe 2000). The final step in the conjoint analysis process is data analysis (Ryan and Farrar 2000). The random effects multinomial logit model in Sawtooth software was used to analyze the data. Effects coding was used to scale the sum to zero within each attribute for determining conjoint utilities/value to the patient (Orme 2010). The relative importance of the side effects was obtained by averaging the absolute values of the attribute level coefficients across levels of attributes, including the baseline coefficients. WTP was estimated as the amount respondents were willing to pay to avoid each side effect level and have a baseline level of no or minimal side effect. This was calculated by dividing the coefficient differences between the baseline level of no or minimal side effect and the respective side-effect level by the coefficient for out-of-pocket cost (Orme 2010).

The survey was fielded as an online, self-administered survey to MBC patients. Patients were identified from a US consumer panel of breast cancer patients and were sent an email link to complete the survey. Respondents were compensated (gift certificate, $<\$ 25$ ) for their time for completing the survey. Survey respondents completed 15 conjoint analysis questions in addition to background demographic questions and questions on their history of side effects while on MBC treatments.

\section{Results}

There were a total of 298 respondents. The majority of respondents were white (84\%), married (57\%), over 40 years old (86\%), and had private insurance (57\%). Respondents were evenly distributed across the country and mostly resided in suburban areas (53\%). Most respondents had a degree (associates or higher) and a household income above $\$ 50,000$ (53\%) (Table 2).

\section{Metastatic breast cancer experience}

Approximately $71 \%$ of patients were receiving treatment for $\mathrm{MBC}$ at the time of the survey. The most common chemotherapies mentioned as part of their current regimen included paclitaxel, trastuzumab, doxorubicin, anastrozole, and cyclophosphamide (Figure 1). The average 


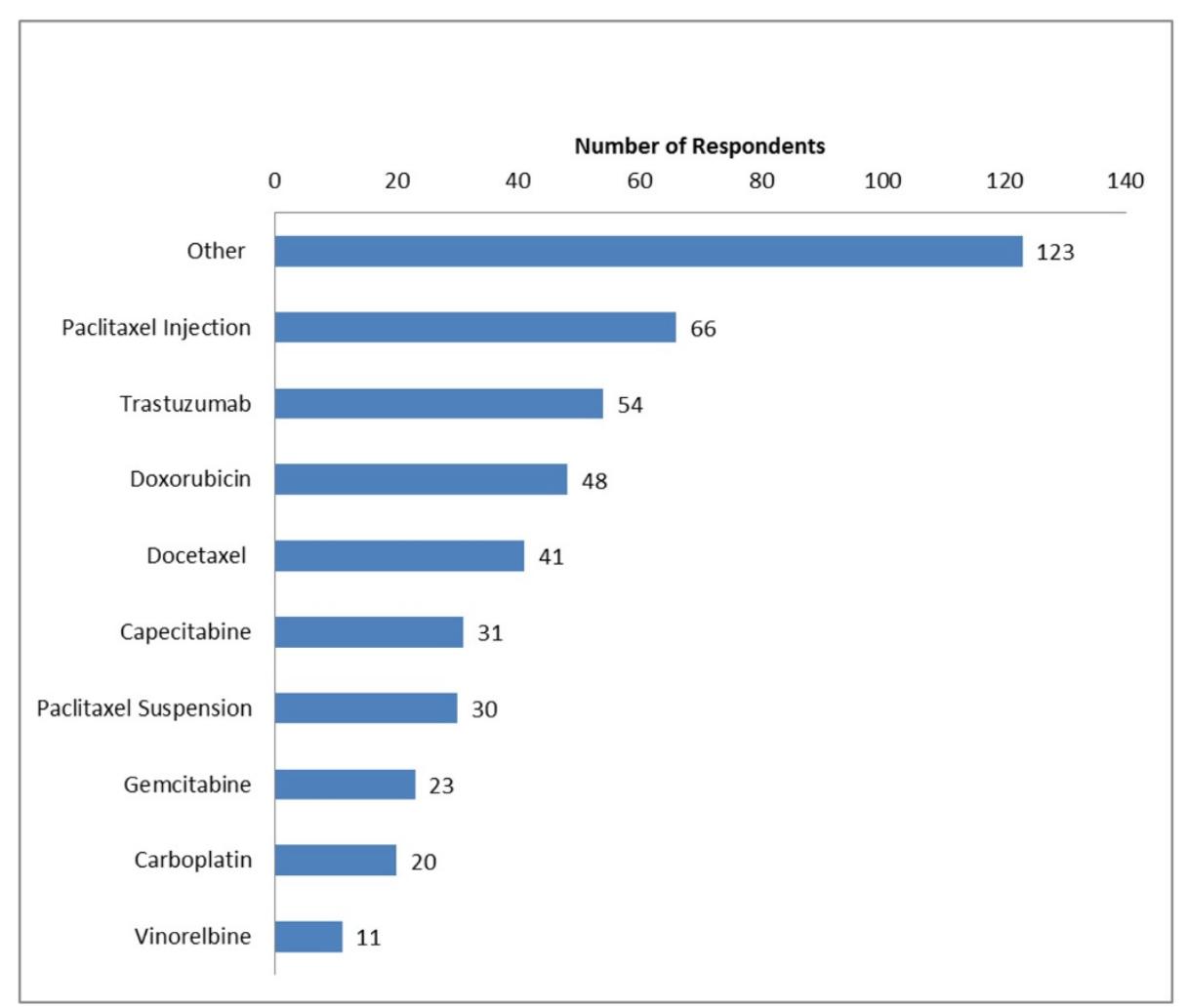

Figure 1 Current or most recent treatment regimen. Other chemotherapy treatments reported were letrozole, zoledronate, ixabepilone, cyclophosphamide, fulvestrant, anastrozole, tamoxifen, exemestane, denosumab, mitomycin, eribulin, leuprolide, pamidronate, lapatinib, raloxifene, ibandronate.

out-of-pocket cost reported by the respondents for their last regimen was $\$ 832$. Most respondents (i) experienced moderate fatigue; (ii) lost none or only some of their hair, and (iii) experienced mild to moderate nausea, pain, diarrhea, and tingling of hands and feet. The impact of side effects on quality of life was closely related to severity of adverse events. As respondents experienced more severe side effects, they reported a more negative quality of life (Figure 2).

\section{Willingness to pay}

Conjoint analysis was used to determine the maximum yearly total out-of-pocket amount that respondents would be willing to pay for an entire course of therapy that would provide equal effectiveness and a reduction in treatment-related side effects. WTP serves as a proxy of patient utility by measuring patients' desire to avoid side effects that can negatively affect the treatment's value to the patient. The side effects that patients were willing to pay the most to avoid were diarrhea so severe they could not leave the house $(\$ 3,894)$, being hospitalized due to an infection $(\$ 3,479)$, nausea so severe that they could not eat $(\$ 3,211)$, and tingling in the hands and feet that interferes with daily activities $(\$ 2,764)$ (Figure 3).

\section{Value to patient}

The average value to patients (part-worth utility) for each attribute was calculated using effects coding. The relative importance of each attribute was determined based on the range of each attribute's utility values. The attributes with the most utility to patients were risk of infection (1.0090), diarrhea (0.8809), and nausea (0.7709) (Table 3).

\section{Discussion}

The results of the analysis indicate that patients were willing to pay over $\$ 3,000$ a year to avoid severe diarrhea, being hospitalized due to infection, and severe nausea. The most important attribute based on utility to patients in treatment decisions was the risk of infection/ febrile neutropenia. In previous conjoint analysis research in patients with breast cancer, neutropenia with hospitalization, nausea, and fatigue were found to have the most impact on patients' preferences for chemotherapy (Beusterien et al. 2012). The results of this analysis are consistent with previous patient preference research using conjoint analysis. Previous research on the health utilities of MBC side effects has shown that febrile neutropenia/risk of infection has a major impact on quality of life (utility -0.150) (Lloyd et al. 2006). The utility for febrile neutropenia was higher than the utility for other 


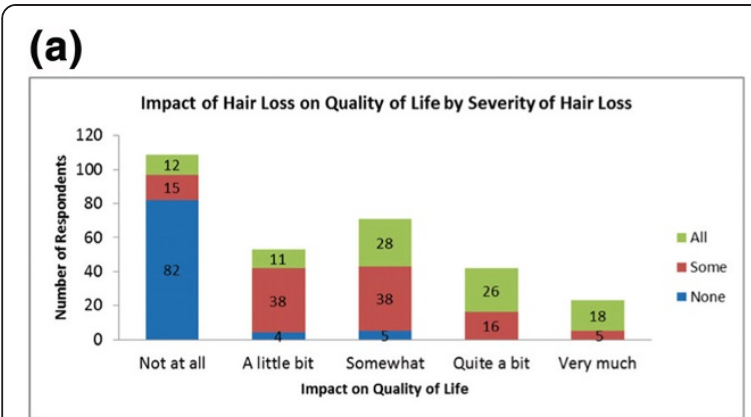

(c)

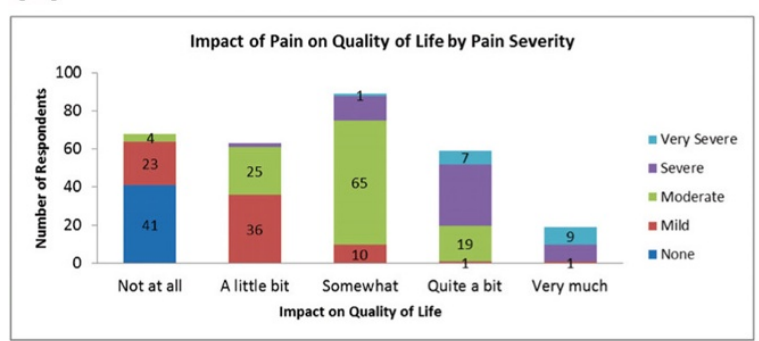

(b)

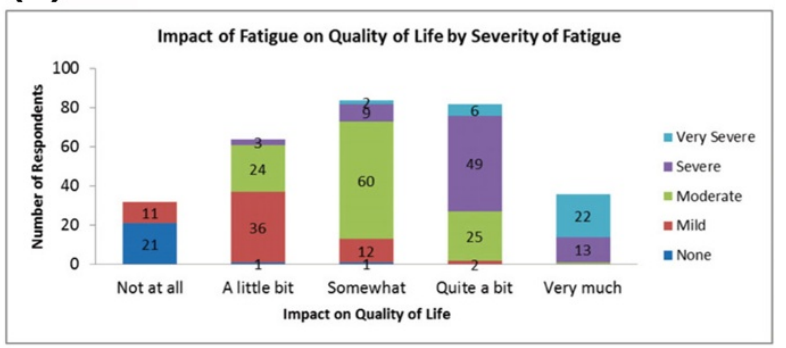

(d)

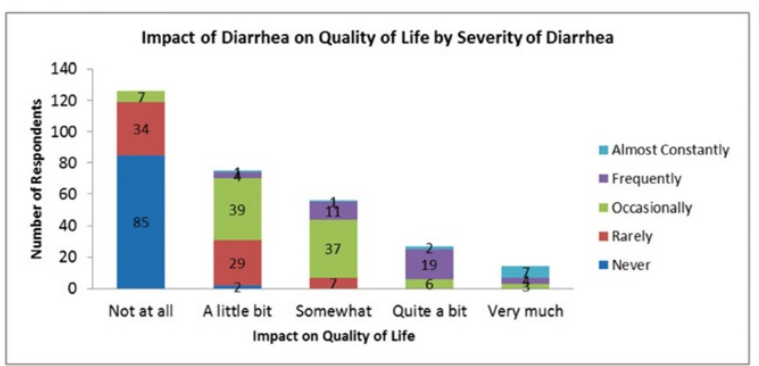

(e)

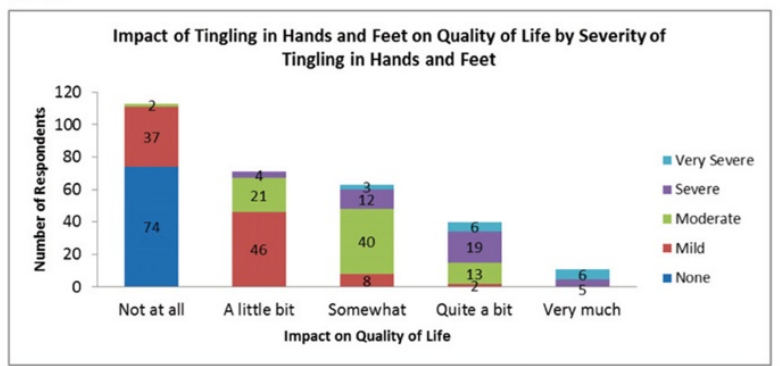

Figure 2 Impact of side effects on quality of life by Severity of Side Effects. (a) Hair loss (b) Fatigue (c) Pain (d) Diarrhea (e) Tingling in hands and feet.

side effects such as hand-foot syndrome (-0.116), fatigue $(-0.115)$, hair loss $(-0.114)$, and diarrhea/vomiting $(-0.103)$ (Lloyd et al. 2006). The utilities of attributes from this analysis are consistent with previous research on the utilities of $\mathrm{MBC}$, with febrile neutropenia having the largest impact on quality of life (Lloyd et al. 2006). In our analysis, diarrhea had higher utility to patients than in previous research. This may be driven by the conjoint methodology and the distribution of levels of diarrhea, with the most severe level of diarrhea leaving the patient in a state where they are unable to leave the house due to the frequency and urgency of diarrhea.

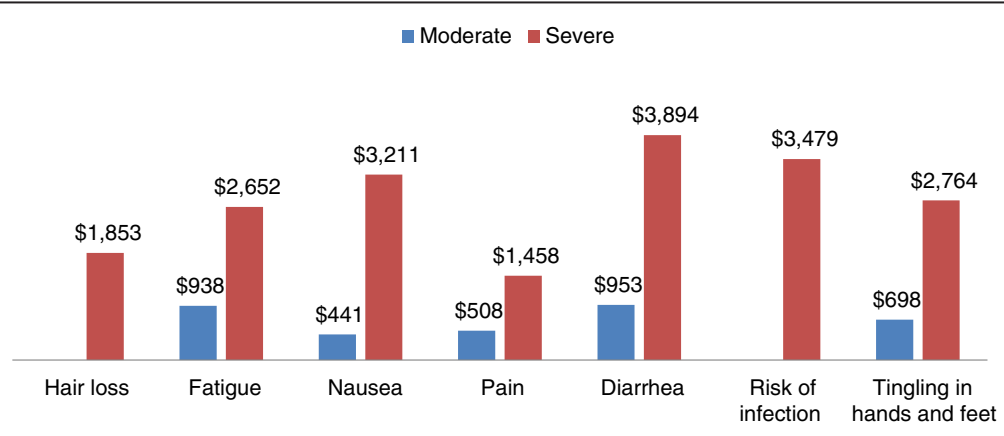

Figure 3 Average yearly willingness to pay for a reduction in treatment-related side effects by Severity of Side Effects. 
Table 3 Average value to patient of a reduction in side effects

\begin{tabular}{|c|c|c|c|c|}
\hline Attribute & Levels & Value to patient & $\begin{array}{c}\text { Average value to } \\
\text { patient }\end{array}$ & Importance \\
\hline \multirow[t]{2}{*}{ Hair loss } & None/not noticeable & 0.5374 & 0.5374 & 6 \\
\hline & Obvious & -0.5374 & & \\
\hline \multirow[t]{3}{*}{ Fatigue } & None/full activity & 0.6941 & 0.5628 & 5 \\
\hline & I often need a nap to reset myself & 0.1501 & & \\
\hline & Major impact on my activity level & -0.8841 & & \\
\hline \multirow[t]{3}{*}{ Nausea } & None/easy to ignore & 0.7060 & 0.7709 & 3 \\
\hline & Manageable with OTC medication (eg, Advil, Tylenol) & 0.0854 & & \\
\hline & Need prescription-strength medication & -0.4654 & & \\
\hline \multirow[t]{3}{*}{ Diarrhea } & 2 stools or less per day & 0.9371 & 0.8809 & 2 \\
\hline & $3+$ loose stools per day & 0.3842 & & \\
\hline & $\begin{array}{c}\text { Unable to leave the house due to frequency and urgency } \\
\text { of diarrhea }\end{array}$ & -1.3213 & & \\
\hline \multirow[t]{2}{*}{ Risk of infection } & None/modest & 1.090 & 1.090 & 1 \\
\hline & Hospitalized due to infection & -1.090 & & \\
\hline \multirow[t]{3}{*}{ Tingling in hands and feet } & None/easy to ignore & 0.6693 & 0.6624 & 4 \\
\hline & Bothersome, but manageable & 0.2643 & & \\
\hline & Interferes with daily activities (eg, getting dressed) & -0.9336 & & \\
\hline
\end{tabular}

The average value to patients is the part-worth utility calculated using effects coding. The relative importance of each attribute was determined based on the range of each attribute's utility values.

The results elicited in this analysis using conjoint analysis are different from those seen when patients are asked directly which side effect they would most like to avoid. In a previous survey of $202 \mathrm{MBC}$ patients, the side effects patients responded that they were most likely to pay extra to avoid were hair loss (28.2\%), pain (16.8\%), and nausea (14.9\%) (Lalla et al. 2011). In the previous survey, patients assessed the importance of each side effect individually without reference to price or the severity of the side effect and without any tradeoffs between attributes. When presented with conjoint questions looking at different scenarios and faced with tradeoffs between attributes, hair loss and pain went from 2 of the most important attributes to the least 2 important attributes in a conjoint analysis.

When presented with an open-ended question to assess how much they would be willing to pay for a $25 \%$, $50 \%$, or $100 \%$ reduction in MBC treatment side effects, respondents were willing to pay $\$ 1,886$ for a $25 \%$ reduction in $\mathrm{MBC}$ treatment side effects, $\$ 3,837$ for a $50 \%$ reduction in $\mathrm{MBC}$ treatment side effects, and $\$ 7,794$ for a $100 \%$ reduction in MBC treatment side effects (Lalla et al. 2011). In the previous survey, patients were willing to pay more to avoid treatment-related side effects when presented with an open-ended response. The difference in the WTP estimates between this study and Lalla et al. (2011) is likely due to the discrete choice framework approach used in the current study, where respondents are effectively locked into the choice between the scenarios presented (Ratcliffe 2000). For example, in our survey, the lowest out-of-pocket cost was $\$ 500$. The respondent may only be willing to pay $\$ 300$ for the scenarios under consideration. The respondent is unable to give his/her true preference as their WTP amount is not a given option. Similarly, the highest out-of-pocket cost in our survey was $\$ 3,000$. There may be some patients who are willing to pay more than $\$ 3,000$ for one of the scenarios, and thus they are unable to give their true willingness to pay value.

\section{Limitations}

This analysis has a number of limitations. First, these results do not specifically correlate WTP with insurance status or other determinants of out-of-pocket costs. Patients were asked to choose scenarios based on the yearly out-of-pocket costs; however, patient factors such as insurance status, socioeconomic background, income level, and comorbid diseases may affect the willingness and ability to pay for MBC treatments. Finally, results from this survey may not be generalizable to the entire MBC patient population. This survey population represents a small subset of the MBC patient population who were healthy enough and willing to complete a 30-minute online survey.

\section{Conclusions}

Patients highly value reductions in side effects associated with $\mathrm{MBC}$ treatment and are willing to pay higher outof-pocket costs to avoid the side effects that cause the 
largest reduction in quality of life. The side effects that had the most value or utility to respondents were risk of infection, diarrhea, and nausea. Although risk of infection was considered by respondents to be the most important side effect, as measured by the average utilities, survey respondents had the highest WTP for avoidance of severe diarrhea. Understanding patients' perspectives and preferences on which side effects they most wish to avoid can aid value-based decision making when selecting between MBC treatment options.

\section{Competing interest}

This research was funded by Genentech, Inc. Xcenda, a consulting company, received funding from Genentech for this study. Author Santos is an employee of Genentech, Author Lalla was employed by Genentech at the time of the study, and authors Carlton, Bramley, and D'Souza are employed by Xcenda.

\section{Authors' contributions}

Authors DL, RC, and TB participated in the conception and design of the study. Authors RC and TB participated in the data collection. Authors RC, $\mathrm{TB}$, and $\mathrm{AD}$ participated in the data analysis. All authors participated in the writing of the manuscript and had final approval of the submitted manuscript.

\section{Author details}

'Palo Alto Outcomes Research, Palo Alto, CA, USA. ${ }^{2}$ Xcenda, Palm Harbor, FL, USA. ${ }^{3}$ Genentech, South San Francisco, CA, USA.

Received: 30 June 2014 Accepted: 1 July 2014

Published: 10 July 2014

\section{References}

Andre F, Slimane K, Bachelot T, Dunant A, Namer M, Barrelier A, Kabbaj O, Spano JP, Marsiglia H, Rouzier R, Delaloge S, Spielmann M (2004) Breast cancer with synchronous metastases: trends in survival during a 14-year period. J Clin Oncol 22:3302-3308

Beusterien K, Grinspan J, Tencer T, Brufsky A, Visovsky C (2012) Patient preference for chemotherapies used in breast cancer. Int J Womens Health 4:279-287

Chia S, Speers C, D'yachkova Y, Kang A, Malfair-Taylor S, Barnett J, Coldman A, Gelmon K, O'Reilly S, Olivotto I (2007) The impact of new chemotherapeutic and hormone agents on survival in a population-based cohort of women with metastatic breast cancer. Cancer 110:973-979

Howlader N, Noone AM, Krapcho M, Neyman N, Aminou R, Altekruse SF, Kosary CL, Ruhl J, Tatalovich Z, Cho H, Mariotto A, Eisner MP, Lewis DR, Chen HS, Feuer EJ, Cronin KA (eds) (2012) SEER Cancer Statistics Review, 1975-2009 (Vintage 2009 Populations). National Cancer Institute, Bethesda, MD, http:/seer.cancer.gov/csr/1975_2009_pops09/, based on November 2011 SEER data submission, posted to the SEER website, 2012

Lalla D, McLaughlin T, Brammer M, Bramley T, Bare A, Carlton R (2011) Willingness to pay for a reduction in the risk of treatment-related side effects in patients with metastatic breast cancer [poster], Presented at the ISPOR 14th Annual European Congress, November 5-8, 2011; Madrid, Spain

Lindley C, Vasa S, Sawyer WT, Winer EP (1998) Quality of life and preferences for treatment following systemic adjuvant therapy for early-stage breast cancer. J Clin Oncol 16(4):1380-1387

Lloyd A, Nafees B, Narewska J, DeWilde S, Watkins J (2006) Health state utilities for metastatic breast cancer. Br J Canc 95:683-690

Orme B (2010) Getting started with conjoint analysis: strategies for product design and pricing research, 2nd edn. Research Publishers LLC, Madison, WI

Osaba D, Slamon D, Burchmore M, Murphy M (2003) Effects on quality if life of combined trastuzumab and chemotherapy in women with metastatic breast cancer. J Clin Oncol 20:3106-3113

Pal S, Dehaven M, Nelson R, Onami S, Hsu J, Waliany S, Kruper L, Mortimer J (2012) Impact of modern chemotherapy on the survival of women presenting with de novo metastatic breast cancer. BMC Cancer 12:435

Pearmain D, Swanson J, Kroes E, Bradley M (1991) Stated preference techniques: a guide to practice, 2nd edn. Steer Davies Gleave and Hague Consulting Group
Phillips K, Johnson R, Maddala T (2002) Measuring what people value: a comparison of attitude and preference surveys. Health Serv Res 37(6):1659-1679

Piccart-Gebhart MJ, Procter M, Leyland-Jones B, Goldhirsch A, Untch M, Smith I, Gianni L, Baslega J, Bell R, Jackish C, Cameron D, Dowsett M, Barrios C, Steger G, Huang C, Andersson M, Inbar M, Lichinster M, Nitz U, Iwata H, Thomassen C, Lohrisch C, Suter T, Ruschoff J, Suto T, Greatorex V, Ward C, Straehle C, McFadden E, Dolci S et al (1995) Trastuzumab after adjuvant chemotherapy in HER2-positive breast cancer. N Engl J Med 353:1659-1672

Ratcliffe J (2000) The use of conjoint analysis to elicit willingness-to-pay values. Int J Technol Assess Health Care 16:270-290

Romond EH, Perez EA, Bryant J, Suman V, Geyer C, Davidson N, Tan-Chiu E, Martino S, Paik S, Kaufman P, Swain S, Pisansky T, Fehrenbacher L, Kutteh L, Vogel V, Visscher D, Yothers G, Jenkins R, Brown A, Dakhil S, Mamounas E, Lingle W, Klein P, Ingle J, Wolmark N (1995) Trastuzumab plus adjuvant chemotherapy for operable HER2-positive breast cancer. N Engl J Med 353:1673-1684

Ryan M (1999) Using conjoint analysis to take account of patient preferences and go beyond health outcomes: an application to in vitro fertilization. Soc Sci Med 49:535-546

Ryan M, Farrar S (2000) Using conjoint analysis to elicit preferences for health care. BMJ 320:1530-1533

Shapiro CL, Recht A (2001) Side effects of adjuvant treatment of breast cancer. N Engl J Med 344:1997-2008

Tannock IF, Boyd NF, DeBoer G, Erlichman C, Fine S, Larocque G, Mayers C, Perrault D, Sutherland H (1998) A randomized trial of two doses of cyclophosphamide, methotrexate, and fluorouracil chemotherapy in patients with metastatic breast cancer. J Clin Oncol 6:1377-1387

doi:10.1186/2193-1801-3-350

Cite this article as: Lalla et al.: Willingness to pay to avoid metastatic breast cancer treatment side effects: results from a conjoint analysis. SpringerPlus 2014 3:350.

\section{Submit your manuscript to a SpringerOpen ${ }^{\mathcal{D}}$ journal and benefit from:}

- Convenient online submission

- Rigorous peer review

- Immediate publication on acceptance

- Open access: articles freely available online

- High visibility within the field

- Retaining the copyright to your article

Submit your next manuscript at $\gg$ springeropen.com 